\title{
Millennials usher us in: Nursing and the emerging virtual environment of care
}

\author{
Marie E. Mugavin ${ }^{1,2}$ \\ 1. Department of Emergency Medicine, School of Medicine, University of New Mexico, Albuquerque, New Mexico, USA. \\ 2. First Choice Community Healthcare, Edgewood, New Mexico, USA.
}

Correspondence: Marie E. Mugavin. Address: Department of Emergency Medicine, School of Medicine, University of New Mexico, Albuquerque, New Mexico, USA. Email: memugavin@salud.unm.edu

Received: May 11, 2014

Accepted: J une 12, 2014

Online Published: July 14, 2014

DOI : $10.5430 /$ jnep.v4n9p69

URL: http://dx.doi.org/10.5430/jnep.v4n9p69

\begin{abstract}
The nursing profession is a complex living system that must continually regenerate and redefine itself to remain viable and to meet emerging environmental challenges. As nursing care of patients moves iteratively from the home to the hospital and now into cyberspace, higher education is necessarily driven to cultivate student growth intrinsically, intellectually, and technologically to accommodate these new contexts of care. Reconceptualizing the nursing paradigm to include basic tenets of quantum physics, the science underlying virtual technology, will foster renewal of the nursing profession and its virtual component, and augment the already heightened consciousness of a new generation of students.
\end{abstract}

\section{Key words}

Nursing, Quantum, Technology, Education, Evolve

\section{I ntroduction}

For centuries, nursing scholars have sought to accentuate and distinguish the depth and breadth of our contribution to healing practices ${ }^{[1]}$. It has become increasingly challenging to do so as our modalities of care and care environments move iteratively from the home to the hospital and now into the ethers, also referred to as cyberspace ${ }^{[2]}$. In cyberspace, human beings connect through computers and telecommunication affording a virtual space to interact, share information, provide social support, and to heal ${ }^{[3]}$.

In this rather revolutionary time, higher education is necessarily driven to cultivate student growth intellectually, spiritually, and technologically to accommodate these new contexts of care. Language embodies these different ways of knowing and helps us construct the incredibly complex knowledge systems we use ${ }^{[1]}$. The language applied in the culture of nursing profoundly shapes how the profession constructs its reality. Students entering nursing programs arrive with many gifts and forms of expression that will help usher in this new virtual reality. They are referred to as Generation Y, but prefer to be called Millennials (named for the first generation to come "of age" in the 21st century) and will make a distinct contribution to theorizing health, body, and nursing in the emerging virtual environments of care ${ }^{[4,5]}$. Reconceptualizing the nursing paradigm to include the basic tenets of quantum physics, the science underlying virtual technology, will foster autopoiesis of the nursing profession and its virtual component, and augment the already heightened consciousness of this new generation. 


\section{A confluence of theories serve new students}

A tapestry of colorful threads provides the backdrop for this theoretical discussion. A mechanistic or "divided whole" view still seeps into the perception and imagination of contemporary society. Nursing theorists like Rogers, Newman and Watson had a unique vision to share which is more in concert with our evolving consciousness about the natural world and the nature of what it is to be nurse, human, healer. Though much of nursing is drawing from middle-range theory in education and practice, the employment of grand theories as paradigmatic guides remains useful and will be brought to the forefront in this discussion. Martha Rogers' Science of Unitary Beings (SUB) is central to the discussion ${ }^{[6]}$.

Nursing knowledge has become increasingly more abstract, having evolved from an emphasis on parts to a focus on the pattern of the whole. Rogers ${ }^{[7,8]}$ work was seminal in that she asserted human beings are dynamic energy fields unified with environmental fields. She credited multiple disciplines with influencing the development of the SUB. They included anthropology, psychology, biology, history, physics, mathematics and literature. Rogers followed in Nightingales footsteps by placing the human being within the framework of the natural world but went further by proposing a set of basic assumptions that describe the life process in human beings. They are wholeness, openness, unidirectionality, pattern, organization, sentience and thought. Rogers then proposed four building blocks for her model: energy fields, a universe of open systems, pattern, and pandimensionality ${ }^{[6-8]}$.

Pandimensionality is an overriding concept for Roger's work. It is the idea of a unitary whole that is nonlinear without spatial or temporal attributes that continuously creates, recreates and evolves itself. Essentially the health of a human being is a unitary phenomenon, an aspect of the unitary whole. Energy signifies the dynamic nature of a field that includes all living things. A human being exists as a continuous, mutual process with the environment. Although Rogers did not clearly define health, she noted that positive health involves one creating opportunities for rhythmic, fluid interactions with another.

Newman ${ }^{[9]}$ also encouraged a shift from purely mechanistic frameworks to the integration of abstractions in her health as expanding consciousness theory that bridged the mundane and the increasingly more complex. Her work, an extension of exceptional theorists such as Rogers ${ }^{[6,7]}$, Bohm ${ }^{[10]}$, and Prigogine ${ }^{[11]}$ carries the threads of consciousness, pattern, environment, person and health. In Newman's theory, consciousness involves the interconnectedness of an entire living system including its inherent capacity to exchange information ${ }^{[9]}$. Expanding one's consciousness is a process whereby an individual becomes closer to him or her authentic self. Nurses are conduits for that evolution. They can help patients find meaning by incorporating rhythmic patterns in the nurse/patient interaction. The insight derived during the transaction provides clients with possibilities for transformation ${ }^{[9]}$.

Watson's ${ }^{[12]}$ Theory of Human Caring suggested nurse's caring consciousness is expressed in frequencies. Higher energy frequencies have more healing potential than lower frequencies that resonate in non-caring consciousness. Healing may be created with the application of varying modalities that are energetic in nature, such as form, color, light, sound, sight, and touch. The underlying sentiment is that when one has the skills and training, he or she is able to transmit feelings of caring and demonstrate competence, both of which have healing potential.

The theories of Rogers ${ }^{[6,7]}$, Newman ${ }^{[9]}$ and Watson ${ }^{[12]}$ all embody nuances of the quantum world and capture the essence of nursing care at both the macro level (direct patient care) and the micro level (transcending physicality). The work of these theorists provides vital tools that may be used to advance the nursing profession toward conceptualizing and incorporating itself into the virtual environment. As a natural extension new nurses are being asked to appreciate that nature is infinite in its potential and depths of subtlety ${ }^{[13]}$. Adding linguistic nuance to the nursing paradigm will acquaint students to the notion that we are images of a higher process that we have the potential to resonate at a more refined timbre and to exist in all dimensions and on all planes simultaneously. In other words, if we extend our thinking beyond the constructs and the assumptions currently inherent in our practice, we will be increasingly more present in the quantum level energy of healing. 


\section{The quantum world, telemedicine, and virtual reality simulation}

The nursing profession is a complex living system that must engage in autopoiesis to survive. Autopoiesis is life's fundamental process of creating and renewing self, with growth, change, and redefinition inherent in the process ${ }^{[14]}$. According to Prigogine ${ }^{[11]}$, a system must be willing to let go of its present form so it can reorganize in a direction that is better suited to the demands of its changing environment. Anything that disturbs the system plays a crucial role in helping it self-organize into a new form of order ${ }^{[15,16]}$. In the case of nursing, stretching student and faculty understanding of paradigms outside the biomedical model that inform our practice may be uncomfortable or disruptive initially, but will evolve the profession, allowing it to transform into a higher level of complexity and to face challenges with more composure.

The advancement of virtual technology in health care mandates that the nursing profession not only reconceptualizes basic assumptions of the nurse-patient exchange, but understands this new medium as the successful application of quantum physics and its rudimentary underpinning: process. The notion that reality can be understood as process is an old one. Its essence is that everything changes and is in fact, always in flux. Changes occur on the quantum level, where energy transforms into matter ${ }^{[17,20]}$. It is in this field of pure potentiality that healing takes place. If one could recognize the fluidity of interchange from the quantum to the material level and the elusiveness of what we consider reality, an expanded space for healing would reveal itself. At this level of fluidity normal cells transform into malignant cells and a malignant process transitions back to normal cellular reproduction ${ }^{[18,20,21]}$. This pure medium from which caring and, thus, the therapeutic nursing process manifest has been considered by many individuals including Einstein to represent a higher consciousness or life's original source ${ }^{[18,22,23]}$.

Applications of this knowledge are found in the burgeoning fields of telemedicine and virtual reality simulation ${ }^{\text {[24-26] }}$. Telemedicine is a nascent paradigm of health care delivery that integrates information and communication technology with health care. Disease management is generally based on history, biochemical reports and imaging, all of which can be transferred electronically to a health care provider anywhere in the world. This modality has enhanced the lives of marginalized individuals with chronic illnesses by making healthcare more accessible. It has facilitated treatment of cardiac emergency cases in real time and in doing so, saved lives. Challenges of escalating health care costs and of taking modern medicine to rural and remote areas are being more efficiently managed with the expanding use of telemedicine ${ }^{[27,28]}$.

Virtual reality simulation-based training is a highly technical physics-based practice used by nursing faculty, the military, aviation, medicine, the nuclear power industry, music and in professional sports. The method became essential to nursing education due to a shortage of health care agencies available to accommodate an increasing number of students. Virtual reality training allows students to experiment with different practice choices, the resulting patient outcomes and opportunities to self-correct. This is an invaluable benefit in that there is no real risk of injury to the "patient" and there are continued assessments providing learner specific feedback. Students are able to absorb abstract concepts the very moment they are immersed in a specific field of patterns. The technology also affords experiences such as moving fluidly through an organ system or through the entire body, endeavors that would otherwise be impossible to accomplish ${ }^{[2,29-31]}$.

\section{Expanding the nursing paradigm: A quantum view}

As science and technology evolve, so too will the profession of nursing ${ }^{[43]}$. It is necessary however, to absorb language that reflects the evolving lens through which we experience the world. The current nursing paradigm including environment, person, health, and nurse will be reconceptualized and expanded upon to reflect emerging themes in the virtual world. 


\subsection{Environment}

Quantum physics is the most fundamental of the natural sciences with a philosophical commitment to simplicity. It is an analysis of nature devoted to better understanding how the universe behaves on a micro level and how it may be expressed on a macro level. Environment in this context is a collective whole that is expressed in the form of particles, fields and the varying patterns inherent therein ${ }^{[10]}$. In the most mundane terms, environment can be described as a place where information is exchanged, where things happen, things exist, and things transform or come to life; it is aggregate by nature. On the quantum level, the concept of environment is rife with subtleties. A quantum particle is actually a temporary localized pulse emerging from a larger field. The action or movement of these quantum entities is discontinuous involving discrete pulses or packets of energy that jump from one energy state to the next without passing through intermediary states. This behavior implies a universe woven together in a dynamic tapestry-like configuration that may appear random at first glance ${ }^{[32,33]}$.

Because it is unwise to assume a definitive viewpoint, scientists continue to ask questions about the nature of particles, fields, and other aspects of environment. Recently François Englert and Peter Higgs were jointly awarded the Nobel Prize in Physics for the theory of how particles acquire mass. The discovery of the Higgs particle is a central part of the Standard Model of particle physics that describes how the world is constructed. Everything, from flowers and people to stars and planets, consists of just a few building blocks - matter particles. There is both a Higgs particle and a Higgs field. The Higgs particle originates from an invisible field that encompasses all space. Even when the universe seems empty the field is present providing particles their mass. The Higgs particle then provides all other elementary particles their mass (weight). Without mass the elementary particles would race around frenetically - and would be unable to form atoms. The Higgs field is commonly conceptualized as sticky syrup through which the particles travel. As the particles move through the syrup, the dense liquid adheres to them. This abstract yet exquisite finding offers an explanation for how the most basic building blocks of the universe acquire mass which eventually forms the world we know today. It is the equivalent in significance of the discovery of the atom upon which many of our medical and social technologies are based. The Higgs particle has in fact, been referred to as the ever elusive "God particle" ${ }^{[34-37]}$. All these elements of the environment exist in continuity and influence the healing potential of the nurse and person.

\subsection{Person}

Person and environment maintain a reciprocal relationship in that they mutually transform one another. The concept of person cannot be adequately defined or completely knowable just like the law of nature cannot be reduced to a set of edicts that are in principle finite and knowable. Nursing theorists have suggested that individuals are recognized by their unique patterns which are continuously shifting from orderly to disorderly states, and referred to as health and disease, respectively ${ }^{[7-9,12]}$. These concepts align with quantum physics in that patterns are understood to transcend boundaries of human physicality that make it possible to differentiate between one another. The energy that is expressed in body and spirit for instance, is in a constant state of regeneration or flux; there is no static state - simply an ongoing exchange of information ${ }^{[10]}$. Resonating from the energy is consciousness. To our knowledge consciousness has no shape, form, or color as it is not easily investigated or understood ${ }^{[38]}$. At this juncture we settle on a person being a fluid, elegant constellation of energies that employs the catalyst energy of consciousness to transform and transcend (in this case disease).

\subsection{Health}

Health is a perceived state of illness or well-being. A person can participate in creating good health and countering bad health. Health may also be distinguished as energy groupings that participate in active transmutations on the quantum level. It is a field that initiates a condition in space ${ }^{[9,39]}$. The field draws particles of similar energy content and momentum. The Higgs field was referred to as sticky syrup through which particles travel ${ }^{[35,36]}$. Metaphorically health and illness may be considered fields of sticky syrup that were formed by the accumulation of lifestyle choices, environmental and genetic 
factors and an individual's relationship with self and spirit. Particles attracted to the individual fields add momentum to the subtle health-related energetic changes therein.

\subsection{Nurse}

In the paradigm presented "nurse" is the fruition of transformative energy in diverse milieus of care including person, environment (both virtual and energetic) and health. Nurses heal by employing forms of knowing that involve creativity, process, engaging unspoken dialog, and the capacity to think critically about oneself and a given situation. They integrate all levels of perceived reality; all energy forms including particles, fields, and human consciousness. The discovery of the Higgs particle and Higgs field affords opportunity to transcend the artificial boundary between science and experience and to embark upon intensive study of the structure of human subjectivity ${ }^{[34-39]}$. Human subjectivity which largely encompasses consciousness is the nurse's milieu. Mastery of this burgeoning aspect of physics will embolden the profession and its capacity for healing. Presently, the nurse embodies the depth and breadth within which to fuse abstractions, higher consciousness and practice. The stage is set.

\section{Nursing and the virtual environment}

We are largely unaware of the degree to which heritable paradigms dominate our perception and thought. The virtual environment requires nurses reconstruct their identities and challenges scholars and faculty members to embark on philosophical inquiries concerning the nature of being and knowing, including conceptions of place, presence, and environments of care. In this realm, nurses and patients may not meet in proximate space ${ }^{[1,2,29,31]}$. The change commands more than a modicum of creativity, as it calls into question how nurses will communicate caring and competence to patients they are treating virtually. The fundamental challenge is to create a feeling of presence and a sense of shared space without actually being physically present.

At this juncture, computer engineers, nurses, and nursing faculty share a common interest in the creation and effective use of presence, as well as how to generate its effects. Design goals include overcoming the effects of distance and the simulation of more immediate personal encounters ${ }^{[31]}$. The question is whether nurses will be able to let go of perceived certainties, such as the belief that healing occurs exclusively through proximate contact with a physical body, and whether they will risk embracing the healing potential manifest in a new medium. In contemplating this possibility, we may once again draw perspective from the domain of quantum physics. In contrast to Newtonian or classical laws of motion, quantum physical laws do not allow us to determine certainties, but only to consider possibilities ${ }^{[10]}$. If we align ourselves with the quantum view of life, it opens our minds to all that exists both in and outside the proverbial "box".

If we allow ourselves to dive down deeply into the nature of matter, everything we know about the everyday world dissolves. There are no objects anymore, there are only relationships. There is no locality. Thus, by being observers and participants in telemedicine, nurses are capturing the essence of relationships, transcending physical boundaries, and becoming part of the landscape of healing. The Millennials are already invested observers and masters of digital media, with the capacity to facilitate this level of interplay. Partnering these attributes with in-depth knowledge of foundational nursing theories will empower students to conceptualize and demonstrate abstract concepts, such as caring, intention, and presence in the virtual world.

\section{Millennials usher us in}

According to Howe \& Strauss ${ }^{[4]}$, Millennials are technology veterans, harder workers and better community builders than any generation since the "greatest generation". Through the use of digital media, Millennials are developing and superimposing their culture on the rest of the populace. These young adults are learning, playing, communicating, working, and creating communities very differently from their parents and in doing so are fostering social transformation. 
Navigating the virtual world is instinctive; it is not a tool but a natural part of their lives, as reflected in Tapscott's assertion that Millennials are "crystallizing around a new communications medium" ${ }^{[40]}$. The digital world is emerging as part of every discipline, commercial interest, and repository of knowledge. Because it is interactive, malleable, and lacking central control, it is a vehicle for revolutionary change in every social structure and discipline, including nursing. Millennials have unprecedented mobility and powerful tools for inquiry, analysis, self-expression and influence. They are shrinking the planet in ways former generations could never imagine.

By nature, Millennials are engaged when offered the opportunity to learn by doing ${ }^{[41]}$. If taught to identify and deliver excellent models of care early in the educational process, there is a higher likelihood the knowledge will be integrated into practice. This generation has the capacity to transform telemedicine and virtual reality simulation into more pervasive, sophisticated tools of our trade ${ }^{[42]}$. Rogers ${ }^{[7,8]}$ had the foresight to recognize that her great passions, science fiction and nursing science would one day intercept and propel our profession to a more evolved level of care. What she did not realize was that a generation would emerge who inherently, seamlessly embodied her philosophies with a mindset toward advancing her most majestic aspirations.

\section{Role of education in preparing a generation of virtual nurses}

Philosophical foundations for educational trends often reflect the historical context in which they occur. It is time for nursing faculty to reassess their current philosophical base and educational format. When planning change, a good place to start is to study the prospective learners and contemporary lifestyles in an effort to properly frame programs and objectives ${ }^{[44]}$. This will invite evaluation of resources already in place to help facilitate change, and will also provide the opportunity to step beyond the boundaries of their own generational thinking. A positive outcome would be the recognition and appreciation of the diversity found in different generations of nurses. Stevens ${ }^{[44]}$ emphasized that the most important contribution a nursing educator makes to the health of the nation is embodied in students. The faculty member who contributes personal vision through passionate teaching is a role model, with his or her energy fueling the student's development ${ }^{[43,44]}$.

There is a strong reluctance on the part of those committed to the biomedical model to apply concepts drawn from modern physics to biological systems. The feeling runs deep in biology, physiology, and medicine that modern physics describes phenomena that are relevant only to subatomic events and that are essentially inapplicable to the macroscopic world inhabited by living things ${ }^{[45,46]}$. But the emergence and rapid advancement of the virtual health environment underscores the fact that the two are intrinsically connected and relevant to one another's existence. The inclusion of a broad tapestry of scientific frameworks in basic nursing education will reflect state of the science consciousness and create a platform where students learn to think abstractly about patient care while also learning to change a bed or calculate dosages. As intimidating or uncomfortable as it might seem to try to grasp concepts that address both subatomic particles and comforting patients in the same breath, it is of necessity that students be able to accomplish this task.

Educators would benefit by considering that at this juncture, young adults are distinct because of their use of technology with which they fuse their social lives and work activity. They are a self-confident generation that on the whole is racially tolerant, receptive to immigrants and nontraditional family arrangements. They are social creatures that report technology makes life easier and bring family and friends together ${ }^{[42]}$. They have also distinguished themselves as a generation that values their elders which is a very welcome character trait given the nation's population is rapidly aging populations. The implications of these distinguishing features are huge ${ }^{[41]}$. However this generation still needs thoughtful mentoring to succeed. One important consideration when interacting with Millennials is that some lack social decorum as a result of spending an inordinate amount of time in front of their electronic devices ${ }^{[42]}$. These students may require guidance and support while developing the skills of therapeutic interplay. It would require faculty be mindful of the unique developmental process that allows for growth in therapeutic relationships given Millennials repertoire of virtual skills and particular social strengths. Faculty relationships with students that model awareness of self in the context of person, patient, 
and health care environment, and that demonstrate a passion for therapeutic interactions will beautifully complement Millennials strength ${ }^{[3]}$. It is speculated that this generation will be focused on identifying and delivering what they value as exceptional care. Introduction to excellent models of therapeutic nursing early in their education may have marked influence encouraging enthusiasm and passion for excellence in nursing care ${ }^{[41,42]}$.

\section{Conclusion}

One of Roger's hopes for the open-ended nature of all science was that knowledge would continue to evolve to benefit the care of people in an ever-changing world. Clinical practice of the future will be comprised of an array of extraordinary encounters allowing nurses and patients to traverse geographical spaces once largely denied them. Patients will become representations in the form of a digital visual display and the nurse will be a healing presence. The healing properties of nursing care are not quantifiable but are, in essence, abstractions, mercurial, and always in flux. These properties are not unlike the undulations, splashes and currents of a stream; patterns abstracted from the flowing movement, appearing and then all at once dissolving with the flow ${ }^{[10]}$. Nursing is moving to a level of practice that accentuates the essence of what we are and always have been as a profession. Now it is time to incorporate language that reflects the new context of care. Nursing faculty are entrusted with this task and with cultivating gifts of a new generation that is destined to change the face of nursing.

\section{References}

[1] Chinn P, Kramer M. Integrated theory and knowledge development in nursing. 7th ed. Elsevier: St. Louis, MO; 2008.

[2] Sandelowski M. Visible humans, vanishing bodies, and virtual nursing: Complications of life, presence, place, and identity. Advances in Nursing Science. 2002; 24(3): 58-70. PMid:11890195 http://dx.doi.org/10.1097/00012272-200203000-00007

[3] Bell D. An introduction to cybercultures. New York: Routledge; 2001.

[4] Howe N, Strauss W. Millennials rising: The next great generation. New York: Vintage Books; 2000.

[5] Pickover CA. Visions of the future: Art, technology, and computing in the twenty-first century. New York, NY: St. Martin’s Press; 1992. PMid:1504048

[6] Fawcett, J. Analysis and evaluation of contemporary nursing knowledge: nursing models and theories. FA Davis Company Philadelphia, PA, 2000.

[7] Rogers M. Nursing science and the space age. Nursing Science Quarterly. 1992; 5: 27-34. PMid:1538852 http://dx.doi.org/10.1177/089431849200500108

[8] Rogers M. The science of unitary human beings: Current perspectives. Nursing Science Quarterly. 1994; 2: 33-35. http://dx.doi.org/10.1177/089431849400700111

[9] Newman MA. The pattern that connects. Advances in Nursing Science. 2002; 24(3): 1-7. PMid:11890192 http://dx.doi.org/10.1097/00012272-200203000-00003

[10] Bohm D. Wholeness and the implicate order. Boston: Routledge \& Kegan Paul; 1980.

[11] Prigogine I. Omni. (1983, May): 85-121.

[12] Watson, J.A. New dimensions of human caring theory. Nursing science quarterly. 1988; 175-181. PMid:3205483 http://dx.doi.org/10.1177/089431848800100411

[13] Nichol L. The essential David Bohm. New York, NY: Routledge, NY; 2000.

[14] Capra F. The web of life: A new scientific understanding of living systems. New York: First Anchor Books; 1996.

[15] Von Bertalanffy L. General system theory: foundations, development, applications. New York, NY: George Braziller, Inc; 2003.

[16] Resnicow K, Page S. Embracing chaos and complexity: A quantum change for public health. American Journal of Public Health. 2008; 98(8): 1382-1389. PMid:18556599 http://dx.doi.org/10.2105/AJPH.2007.129460

[17] Chopra D. Quantum healing: Exploring the frontiers of mind/body medicine. New York: Bantam Books; 1989.

[18] Chopra D. How to know God: The soul's journey into the mystery of mysteries. New York: Three Rivers Press; 2000.

[19] Pert CB. Molecules of emotion: The science behind mind-body medicine. New York: Scribner Publications; 2003.

[20] Wheatley MJ. Leadership and the new science: Discovering order in a chaotic world. 2nd ed. San Francisco, CA: Berrett-Koehler Publishers; 1999.

[21] Wallace B. Choosing reality: A Buddhist view of physics and the mind. Ithaca, NY: Snow Lion Publications; 1996. 
[22] Hawking S. A brief history of time: From the big bang to black holes. Boston: G. K. Hall Publishers; 1988. 8-9.

[23] Hawking SA. The theory of everything: The origin and fate of the universe. Beverly Hills, CA: New Millennium Press; 2003.

[24] Fischer, HR, Reichlin S, Gutzwiller JP, Dyson A, \& Beglinger C. Telemedicine as a new possibility to improve health care delivery. New York: Springer; 2006.

[25] NLM National Telemedicine Initiative. 2009. Available from: http://www.nim.nih.gov/research/telemedinit.html.

[26] Jeffries PR. A framework for designing, implementing and evaluating simulations used as teaching strategies in nursing. Nursing Education Perspectives. 2007; 26(2):96-103.

[27] Zimmerman PG. Managers forum. Journal of Emergency Nursing. 2000; 26: 493-501. http://dx.doi.org/10.1016/S0099-1767(00)90019-9

[28] Valadez JR. Educational access and social mobility in a rural community college. The Review of Higher Education. 1996; 19(4): 391-410.

[29] Waldby C. The visible human project: Informatic bodies and posthuman medicine. London: Routledge; 2000. http://dx.doi.org/10.4324/9780203360637

[30] Telemedicine. British Medical Journal Web site. http://www.ncbi.nlm.nih.gov/pmc/articles/PMC1121135/ Wootton, R. 2009. Accessed October 14, 2013.

[31] Lombard M, Ditton T. At the heart of it all: The concept of presence. Journal of Computer Mediated Communication. 1997; 3(2): $1-45$.

[32] Wilber K. The eye of the spirit: An integral vision for a world gone slightly mad. Boston: Shambhala Publications; 2001.

[33] Wilczek F, Devine B. Longing for the harmonies. New York: Norton and Co; 1988.

[34] Science. 2012 Dec 21; 338(6114): 1576-82. Available from: http://online.wsj.com/article/SB10001424052702304171804579122832781080304.html. PMid:23258888 http://dx.doi.org/10.1126/science.1232005

[35] Nelson, E. Nobel prize for 'God particle’ discovery prompts deeper questions. Washington Post. October 14, 2013. Available from:

http://communities.washingtontimes.com/neighborhood/consciousness-health/2013/oct/13/nobel-prize-god-particle-discovery-p rompts-deeper-/. Accessed October 14, 2013.

[36] God particle scientists win Nobel Physics Prize. The Nation. Available from: http://www.nation.com.pk. Published 2013. Accessed October 13, 2013.

[37] Wolchover, N. How the Higgs Boson gives things mass. Available from: http://www.livescience.com/34045-higgs-particle-mass. html Published 2012.

[38] Lamme, V.A. Towards a true neural stance on consciousness. Trends In Cognitive Science. 2009; 10(11): $494-501$. PMid:16997611 http://dx.doi.org/10.1016/j.tics.2006.09.001

[39] Wolchover N.How the Higgs boson gives things mass. Livescience Retrieved October 14, 2013.

[40] Tapscott D. Growing up digital. New York: McGraw Hill; 1998.

[41] Taylor P, Keeter, S. eds, Millennials: A portrait of generation next. Confident, Connected, Open to change. Available from: http://www.pewresearch.org/millennials. Published 2010.

[42] Weiler A. Information-seeking behavior in generation Y students: Motivation, critical thinking, and learning theory. Journal of Academic Librarianship. 2004; 31(1): 46-53. http://dx.doi.org/10.1016/j.acalib.2004.09.009

[43] Lennerts MH. Teaching personal knowledge as a way of knowing self in therapeutic relationship. Nursing Outlook. 2003; 51(4): 158-164. http://dx.doi.org/10.1016/S0029-6554(03)00116-7

[44] Stevens KR. Teaching vision and passion. Journal of Nursing Education. 1995; 34(3): 99-101.

[45] Dossey L. Time, space \& medicine. Boston: Shambala Publications; 1982.

[46] Dossey L. Reinventing medicine. San Francisco: Harper; 1999. 